\title{
Trends of growing human organ in farm animal's body, review paper
}

\begin{abstract}
Farm Animals and their products have a longstanding and successful history of providing significant contributions to human. There is a huge gap in supply versus demand of human organs for transplantation. Human organs are being grown inside sheep and pigs in a bid to save the lives of those on organ donation waiting lists. Scientists in Japan plan to start systematically growing human organs inside of pigs within 12 months. The goal is to increase the number of organs available for medical transplants. Japan's government is creating new guidelines for scientists to govern them as they grow human organs inside animals. Researchers in USA are taking human stem cells, injecting them into animal embryos, and then implanting into a sheep or pig where they were gestate and possibly be able to provide viable organs to human. Ethical arguments expressed about transplantation from transgenic animals to human are wide and have various ranges, based on their subject and they are the arguments in two main categories: "deontological" and "consequential list.
\end{abstract}

Volume 8 Issue 6 - 2018

\author{
Habtamu Alebachew \\ Ethiopian Institute of Agricultural Research, Ethiopia
}

Correspondence: Habtamu Alebachew, Ethiopian Institute of Agricultural Research, Assosa Agricultural Research Center, PO Box 265 Assosa, Ethiopia, Email hadtamu2005@yahoo.com

Received: February 12, 2018 | Published: November 27, 2018

Keywords: farm animal, human organ, transplantation

\section{Introduction}

There is a huge gap in supply versus demand of human organs for transplantation. There is a need to bridge this gap either by motivate more people to allow organ donation or rely on alternative methods such as improved artificial organ support systems (dialysis machines, bio artificial liver) or search for better ways to circumvent the problems, mainly immunological, with xenografts. ${ }^{1,2}$ This includes improved methods for suppressing host immunity and growing humanized organs in animals. Recent developments with induced pluripotent stem cells (iPSC) have yielded new option-growing organs from pluripotent stem cells derived from the patient's own tissues. Attempts have been made to grow. ${ }^{1}$ Stem cells are cells that can specialize into the many different cells found in the human body. Researchers have great hopes that stem cells can one day be used to grow entire organs, or at least groups of specialized cells. ${ }^{3}$ Xenotransplantation using organ grafts from non-human animals is a possible solution, but the less human the organ the more likely the recipient is to suffer from organ rejection by the immune system. ${ }^{4}$ But simply using the animal body as a bay for maintaining fully organs until needed is another matter and the effort now is to grow the human organ, or humanized animal organ, within the animal and leave it there until needed. ${ }^{5}$ Apparently, it is now even possible to grow entire human organs inside animals. In fact, scientists in Japan plan to start systematically growing human organs inside of pigs within 12 months. ${ }^{5,6}$ The goal is to increase the number of organs available for medical transplants. But once a human organ is grown inside a pig, that pig is no longer fully a pig. And without a doubt, that organ will no longer be a fully human organ after it is grown inside the pig. ${ }^{5}$ Therefore the objective of this paper was to review the trends of growing human organ in farm Animals body and importance of growing human's organ in farm animal's body for the society.

\section{History of cross-species organ transplantation}

Cross-species transplantation (xenotransplantation) offers the prospect of an unlimited supply of organs and cells for clinical transplantation, thus resolving the critical shortage of human tissues that currently prohibits a majority of patients on the waiting list from receiving transplants. Between the $17^{\text {th }}$ and $20^{\text {th }}$ centuries. ${ }^{7}$ Blood was transfused from various animal species into patients with a variety of pathological conditions. Skin grafts were carried out in the $19^{\text {th }}$ century from a variety of animals. ${ }^{8}$ The first heart transplant in a human ever performed was by Hardy in $1964 .{ }^{9}$ Using a chimpanzee heart, but the patient died within 2 hours. Starzl carried out the first chimpanzeeto-human liver transplantation in 1966; in 1992, He obtained patient survival for 70 days following a baboon liver transplant. With the advent of genetic engineering and cloning technologies, pigs are currently available with a number of different manipulations that protect their tissues from the human immune response, resulting in increasing pig graft survival in nonhuman primate models. Genetically modified pigs offer hope of a limitless supply of organs and cells for those in need of a transplant.?

\section{Human organs are being grown inside sheep and pigs to save the lives of people}

Human organs are being grown inside sheep and pigs in a bid to save the lives of those on organ donation waiting lists. More than 50 sheep and pigs have been implanted with human-animal hybrid embryos with the aim of them developing into fully functional human hearts, livers and other major organs. ${ }^{10}$ Although these techniques have yet to arrive in Britain, the Government's animal research advisers are expected to make them legal when the first full guidelines are published, The Times reported. The experiments rely on a cuttingedge fusion of technologies, including recent breakthroughs in stem-cell biology and gene-editing techniques. By modifying genes, scientists can now change the DNA in pig or sheep embryos so they are genetically incapable of forming a specific tissue. Then, by adding stem cells from a person, they hope the human cells will take over the job of forming the missing organ, which could then be harvested from the animal for use in a transplant operation. ${ }^{11}$

\section{Growing human organs inside pigs in Japan}

The Japanese team then introduces stem cells from a black pig into 
the embryo. What they have discovered is that as the pig develops, it is normal except for its pancreas, genetically a black pig's. In a lab at Tokyo University, Professor Hiro Nakauchi is taking the next step. He takes skin cells from an adult brown rat. ${ }^{12} \mathrm{He}$ then uses gene manipulation to change these adult skin cells into induced pluripotent stem cells (iPS) cells, which can develop into any part of the animal's body. Nakauchi has succeeded in using these iPS cells to grow a brown rat pancreas inside a white mouse. ${ }^{13}$ The result, he hopes, will be a pig with a human pancreas or kidney or liver, or maybe even a human heart. Not only that, the organ would be genetically identical to the human from which the skin cells were taken. ${ }^{14}$ This is one of the holy grails of medical research: the ability to reproduce a human organ that is genetically identical to the person who needs it. It could mean an end to donor waiting lists, and an end to problems of organ rejection. ${ }^{14}$

Apparently, it is now even possible to grow entire human organs inside animals. In fact, scientists in Japan plan to start systematically growing human organs inside of pigs within 12 months. The goal is to increase the number of organs available for medical transplants. But once a human organ is grown inside a pig, that pig is no longer fully a pig. And without a doubt, that ${ }^{5}$ Japan's government is creating new guidelines for scientists to govern them as they grow human organs inside animals. The project could be underway sometime next year and the likely animal species chosen will be pigs. The work entails planting human stems cells into the embryo of animals to make a 'chimeric embryo' which will then be planted into an animal's womb. The intention is to grow them inside the animals and then kill the animals and harvest the human organs for transplants. Livers, pancreas and hearts are among the organs they intend to grow. There is widespread support for this work in Japan but in other countries there are questions about such experimentation. Japanese scientists can now only develop chimeric embryos in a laboratory for 14days and scientists say they've been working hard to get those guidelines changed. ${ }^{15}$

\section{Growing human organ in farm animal body in USA}

Researchers are utilizing human stem cells, animal embryos and farm animal surrogates in hopes of creating a new way to harvest usable organs for those waiting on the extensive transplant list in USA. The researchers are taking human stem cells, injecting them into animal embryos, and then implanting into a sheep or pig where they were gestate and possibly be able to provide viable organs to human. ${ }^{16}$ While the United States does not regulate chimeras, this research is not without its fair share of naysayers. Because the human cells are injected into the animal cells early on in the development of the embryo, it is possible for the human cells to multiply, specialize, and potentially contribute to any part of the animal's body as it develops according the report. ${ }^{17}$

\section{The contribution of farm animals to human health}

Farm animals and their products have a longstanding and successful history of providing significant contributions to human nutrition, clothing, and facilitation of labour, research, development and medicine and have thus been essential in improving life expectancy and human health. ${ }^{18}$ With the advent of transgenic technologies the potential of farm animals for improving human health is growing and many areas remain to be explored. Recent breakthroughs in reproductive technologies, such as somatic cloning and in vitro embryo production, and their merger with molecular genetics tools. ${ }^{18}$ The contribution of farm animals to human health, covering the production of antimicrobial peptides, dietary supplements or functional foods, animals used as disease models and the contribution of animals to solving urgent environmental problems and challenges in medicine such as the shortage of human cells, tissues and organs and therapeutic proteins. Some of these areas have already reached the level of preclinical testing or commercial application, others will be further advanced only when the genomes of the animals concerned have been sequenced and annotated. Provided the necessary precautions are being taken, the transmission of pathogens from animals to humans can be avoided to provide adequate security. Overall, the promising perspectives of farm animals and their products warrant further research and development in this Field. ${ }^{19}$

\section{Ethical issues of transplanting organs from transgenic animals into human beings}

Today, organ transplantation has attracted many attentions, and has socially caused a lot of worry. The main problem is the imbalance between the organ transplant request and the number of organs ready to transplanting. At present, patients tolerate not only the pain caused by organ malfunction but also psychological tensions while waiting to receive healthy organs. ${ }^{20}$ Historical studies have indicated that with developing skills and knowledge in the field of medicine, human has increased his exploitations of animals in order to transplanting their tissues and organs into human beings. ${ }^{21}$ Various examples of transplanting animal's organ into human can be reported, but the common fact is that lifespan of the recipient after the operation was very short and that all patients died in various stages of acceptance. ${ }^{22}$ A major problem in organ transplant from animal to human is recipients' immune response. The transplanted organ is identified as alien. Therefore, the immune system rejects it to protect the body ${ }^{23}$ Based on time, this immunological reaction occurs in three forms of hyper-acute, acute, and chronic rejections. In the first form, the transplanted organ is rejected within only seconds or minutes after the transplantation; in the second form, this rejection happens after some days to a week; and in the third, in longer-term, within some weeks to years. ${ }^{24}$

Ethical arguments expressed about transplantation from transgenic animals to human are wide and have various ranges, based on their subject and nature. ${ }^{25}$ They are the arguments in two main categories: "deontological" and "consequentialist. ${ }^{26}$ In the first group, ethicists believe that the very nature of such an action is unethical and unacceptable regardless of the consequences of procedure and its effects on human or animals. In the second group, the transplant process is regarded as unacceptable because the contradictory outcomes occur for both humans and animals. ${ }^{26}$ On the other hand, the proponents of the animal welfare believed that human has a right to use animals in order to meet his needs if the animal suffering and the costs of use is less than the benefits to humans. ${ }^{27}$ Regarding the use of animals' organs in transplantation into human, some of the supporters of the animal rights have disagreed strongly about human's using animals for any kind of their needs through emphasizing on equal rights of animal and human being. As a result, from their point of View, torturing and killing animals to transplant their organs to human beings is unethical and means lowering animals' status to things or to a tool box. ${ }^{28}$ Along with this point of view, another group of animal ethics philosophers, especially utilitarian philosophers like Peter Singer, have not refused the idea of using animals for saving human life, and in contrast, only through attribution requirements, they have tried to limit and to decrease the quantity and quality of such a use. ${ }^{29}$ Based on the broad definition, the goal, in addition to keeping the 
animal away from negative factors, is to give a chance to animal to show its species-specific behavior and live according to its type. In other words, in this definition of animal welfare, the concept of being natural is highly emphasized. ${ }^{30}$

Therefore, genetic modification of animals is basically the total destruction of their welfare because the integrity of animal genome is manipulated to create an animal which is different from its natural type. Furthermore, in order to prevent transfer of any kind of virus, these animals should be kept in a completely quarantined place and be imprisoned. This has caused a lot of ethical criticism, because keeping animals imprisoned in a place that is not similar to its natural habitat, far from any interaction with its kind, takes its chance to live naturally. The broad definition of animal welfare is close to the animal right school, so, it seems that welfare of the animals cannot be provided with this definition in most of the farms and labs.

\section{Summery and concussion}

Farm Animals and their products have a longstanding and successful history of providing significant contributions to human nutrition, clothing, and facilitation of labor. Recent breakthroughs in reproductive technologies, such as somatic cloning and in vitro embryo production, and their merger with molecular genetics tools, challenges in medicine such as the shortage of human cells, tissues and organs. Historical studies have indicated that with developing skills and knowledge in the field of medicine, human has increased his exploitations of animals in order to transplanting their tissues and organs into human beings and human organs are being grown inside Farm animals body like sheep and pigs in a bid to save the lives of those on organ donation waiting lists. It is now even possible to grow entire human organs inside animals. Japanese scientists are expecting to be granted approval to grow human organs in animals and then harvest them for transplant within the next year, and scientists in Japan plan to start systematically growing human organs inside of pigs within 12 months. The goal is to increase the number of organs available for medical transplants. Ethical arguments expressed about transplantation from transgenic animals to human are wide and have various ranges, based on their subject and they are the arguments in two main categories: "deontological" and "consequential list. In the first group, ethicists believe that the very nature of such an action is unethical and unacceptable regardless of the consequences of procedure and its effects on human or animals. In the second group, the transplant process is regarded as unacceptable because the contradictory outcomes occur for both humans and animals.

\section{Acknowledgments}

None.

\section{Conflicts of interest}

The author declares that there is no conflicts of interest.

\section{References}

1. Sanal MG. Future of liver transplantation: non-human primates for patient-specific organs from induced pluripotent stem cells. World $J$ Gastroenterol. 2011;17(32):3684-3690.

2. Weatherall D. Science and the quiet art: The role of medical research in health care. WW Norton \& Company. 1996.

3. Alison MR, Poulsom R, Forbes $\mathrm{S}$, et al. An introduction to stem cells. The Journal of pathology. 2002;197(4):419-423.
4. Fishman JA, Patience C. Xenotransplantation: infectious risk revisited. American Journal of Transplantation. 2004;4(9):1383-1390.

5. David Warmflash. Chimera alert? Myths and facts of human-non-human animal hybrids in medicine. 2015 .

6. Herold E. Stem cell wars: Inside stories from the frontlines. Macmillan. 2015.

7. Cooper DK. A brief history of cross-species organ transplantation. Proc (Bayl Univ Med Cent). 2012;25(1):49-57.

8. Lederer Susan E. Flesh and blood: Organ transplantation and blood transfusion in 20th century America. Oxford University Press. 2008.

9. Hardy James D, Carlos M Chavez, Fred D Kurrus, et al. Heart transplantation in man: developmental studies and report of a case. Jama. 1964;188(13):1132-1140.

10. Krien A. Us and them: On the importance of animals. Quarterly Essay. 2012;(45):1.

11. Daily Mail Reporter. Human organs for transplant are being grown inside sheep and pigs to save the lives of people on organ donation waiting lists. 2016.

12. Onishi A, Iwamoto M, Akita T, et al. Pig cloning by microinjection of fetal fibroblast nuclei. Science. 289(5482):1188-1190.

13. Skene L. Recent developments in stem cell research: social, ethical, and legal issues for the future. Indiana Journal of Global Legal Studies. 2010;17(2):211-244.

14. Cooper DK, Lanza RP. Xeno: the promise of transplanting animal organs into humans. Oxford University Press on Demand. 2000.

15. Daniel Brewer. Japanese scientists to grow human organs in animals, likely pigs. 2012.

16. Dove A. Milking the genome for profit. Nature biotechnology. 2000;18(10):1045-1048.

17. Klein N. The shock doctrine: The rise of disaster capitalism. Macmillan. 2017.

18. Kues WA, Niemann H. The contribution of farm animals to human health. TRENDS in Biotechnology. 2004;22(6):286-294.

19. Wilfried A Kues, Heiner Niemann. The contribution of farm animals to human health Department of Biotechnology, Institut fur Tierzucht, Mariensee, Neustadt, Germany. 2004.

20. Cooper DKC, Ekser B, Tector AJ. A brief history of clinical xenotransplantation. International Journal of Surgery. 2015;23(Pt): 205210 .

21. Fox RRC, Swazey JP. The courage to fail: A social view of organ transplants and dialysis. Transaction Publishers. 1974.

22. Ormandy EH, Dale J, Griffin G. Genetic engineering of animals: ethical issues, including welfare concerns. Can Vet J. 2011; 52(5):544-555.

23. Streilein JW, Ma N Wenkel H, Ng TF, et al. Immunobiology and privilege of neuronal retina and pigment epithelium transplants. Vision research. 2002;42(4):487-495.

24. Williams GM, DePlanque B, Lower R, et al. Antibodies and human transplant rejection. Annals of surgery. 1969;170(4):603-616.

25. Manesh SB, Samani RO, Manesh SB. Ethical issues of transplanting organs from transgenic animals into human beings. Cell Journal (Yakhteh). 2014;16(3):353-360.

26. Kortenkamp KV, Moore CF. Ethics Under Uncertainty: The Morality and Appropriateness of Utilitarianism When Outcomes Are Uncertain. Am J Psychol. 2014;127(3):367-382. 
27. Rollin BE. Animal rights and human morality. Prometheus Books. 1981.

28. Cavalieri P. The Animal Question: Why Nonhuman Animals Deserve Human Rights: Why Nonhuman Animals Deserve Human Rights. Oxford University Press, USA. 2003.
29. Francione G. Rain without thunder: The ideology of the animal rights movement. Temple University Press. 2010.

30. Singh J. The national centre for the replacement, refinement, and reduction of animals in research. $J$ Pharmacol Pharmacother. 2012;3(1):87-89. 